\title{
Key Technologies for Green, Low-Carbon and Energy-Saving Buildings in Financial Street Chang 'an Center
}

\author{
Chen Qing ${ }^{1, a}$, Zhou Yuqi ${ }^{1}$, Huang Yong ${ }^{1}$, Li Bo $^{1}$, Zhang Shiyu ${ }^{2}$ \\ ${ }^{1}$ China Construction First Division Group Construction \& Development Co. ,Ltd, Beijing 100102 \\ ${ }^{2}$ Financial Street Holdings Co., Ltd, Beijing 100032
}

\begin{abstract}
Through the innovation and application of eight key technologies for green, low-carbon and energy-saving buildings, Financial Street Chang 'an Center has become the first project in Beijing to obtain the dual certification of three-star green building and LEED gold building, which has played a good demonstration role in the construction of green buildings of urban complex type.
\end{abstract}

\section{Project profile}

Financial Street Chang 'an Center is located in Gucheng of Shijingshan district, Beijing. The north side is Shijingshan Road (a long line west of Chang 'an street), the east side is Gucheng South Street, the west side is Gucheng No. 2 Road, the south side is Lugu Village Road. The project, with a total floorage of $368740 \mathrm{~m}^{2}$, is a large urban complex integrating office, business and hotel services, including nine 14-32-story towers, five 23 -story skirts and 4-story basement. In this project, the concept of green and environmental protection is carried out throughout the whole life cycle of design, construction and operation. It is one of the first projects in Shijingshan to receive the three-star green logo and the largest green building complex in China since the implementation of the new green building standards on January 1, 2015. It is also the first project in Beijing to obtain the dual certification of three-star green building and LEED gold building.

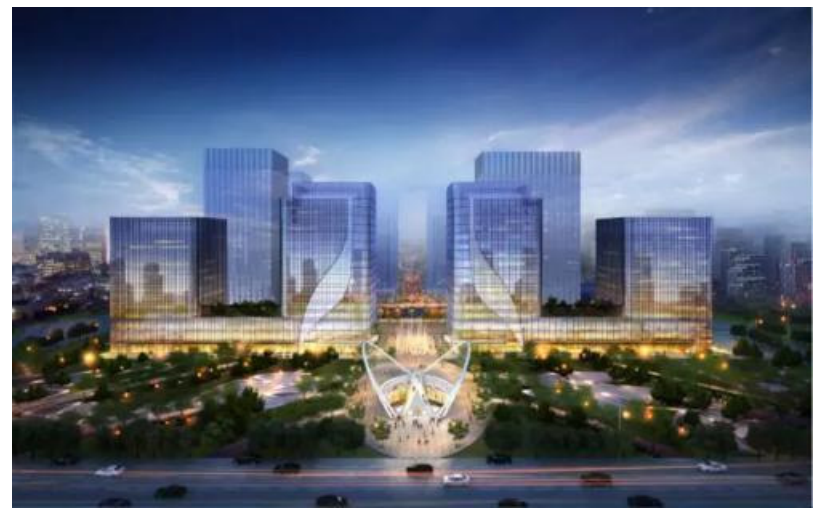

Fig.1 Project renderings of Financial Street Chang 'an Center

In this project, the green building technology involves land saving, energy saving, material saving, water saving and indoor environment, including the comprehensive application of more than 50 technical points. Among them, there are 8 key technologies that have achieved significant benefits. They respectively are: triple glass-two cavities curtain wall system, solar photovoltaic power generation system, high efficiency energy-saving electromechanical system, air cleaning system, building intelligent control system, multiple green system, basement natural lighting system, rainwater control and utilization system, etc.

\section{Technologies for green、low-carbon and energy-saving buildings}

\subsection{Triple glass-two cavities double silver Low-E curtain wall system}

The curtain wall of the project is made of $6+12 \mathrm{Ar}+6+12 \mathrm{Ar}+6$ hollow tempered double silver LowE glass. Tempered glass has been homogenized. The coated surface is the second side of the hollow glass (outside-to-in).The hollow layers are charged with argon gas. The first seal of hollow glass use butyl glue, and the second seal uses silicone structural glue.

The glass is also called infrared shielding glass, which is the top energy-saving product in the current low-E coated glass. It is a special glass formed by coating the inner surface of hollow glass with silver and other metal materials. Because the glass is coated with a metal film, it has a high transmittance to visible light and a high reflectivity to infrared light, which can almost filter sunlight into cold light sources. 


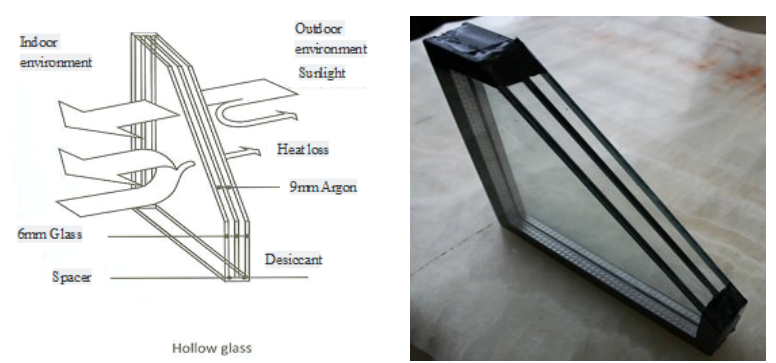

Fig.2 Triple glass-two cavities Low-E curtain wall system

This kind of glass curtain wall can achieve the effect of "warm in winter and cool in summer", which has excellent thermal insulation performance. The unique function of low-E coating is that it has a high reflectance to far-infrared thermal radiation and can reflect more than $80 \%$ of far-infrared thermal radiation back, so it has a good effect of blocking the transmission of thermal radiation. In summer, it can prevent the thermal radiation from the outdoor ground and buildings from entering the room to save the cost of air conditioning and refrigeration. In winter, it can reflect most indoor heating and thermal radiation of object back to indoor like a mirror and ensure that indoor heat does not dissipate to the outside to save the cost of heating. This project adopts double silver Low-E glass which has two function layers (layer of silver). It can block more solar heat radiation than single silver low-E glass and the heat transfer coefficient is lower. It can further improve the thermal insulation performance of curtain wall to really achieve the effect of warm in winter and cool in summer. At the same time, the use of triple glass-two cavities hollow glass makes the energy saving effect more obvious. The heat transfer coefficient of the curtain wall glass in this project is $1.8 \mathrm{~W} / \mathrm{m}^{2} \cdot \mathrm{K}$, which is $18 \%$ higher than the current national standards for building energysaving design. The shading coefficient is 0.33 , which is 27 percent higher than the current national standards for building energy-saving design.

The curtain wall of the project has high visible light transmittance, so the indoor lighting is natural and the exterior effect of the building is transparent. Meanwhile, the visible light reflectance is no more than 0.2 . When the buildings on both sides of the city's main road and overpass are below $20 \mathrm{~m}$, and the buildings on the other sections are below $10 \mathrm{~m}$, the design reflectance is no more than 0.16 . This effectively prevents light pollution to the surrounding environment.In addition, the curtain wall has good sound insulation performance, whose sound insulation volume can reach 38 decibels. It can effectively block the transmission of sound and reduce noise.

The three glass-two cavities double silver Low-E curtain wall system has reduced building energy consumption and provided people with a comfortable and healthy indoor acoustic and optical environment.

\subsection{Solar photovoltaic power generation system}

The total amount of radiation in Beijing is 5038.84 $\mathrm{MJ} / \mathrm{m}^{2}$. According to the hierarchical evaluation method of the abundance of solar energy resources in 'the solar energy resources evaluation method (QX/T 89-2008) ', the region is III class area, namely the 'resource-rich' area. The area has potential and resources to develop solar photovoltaic power generation on a large scale.

The project builds distributed photovoltaic power stations on the roof. The electricity generated by the photovoltaic power station is mainly used in this project. The total installed capacity is $534.05 \mathrm{~kW}$. All power stations use polysilicon battery modules whose specification is $255 \mathrm{Wp}$. The total number of battery modules is 2010 . This project adopts 16 sets of $33 \mathrm{~kW}$ series inverter.

Each building is equipped with the independent power generation unit on the roof. Each power generation unit consists of solar cell module, photovoltaic junction box and inverter. The unit outputs $0.38 \mathrm{kV}$ three-phase alternating current, which is connected to the low-voltage distribution system of the transformer room through the cable. Each power station supplies electrical equipment for each building. Photovoltaic power generation adopts self-use mode.

Photovoltaic power generation system can generate an average of 600,000 degrees of electricity a year which is 2.5 percent of the project's total annual electricity consumption. Compared with the thermal power station, the project can save 6014 tons of coal, reduce the emission of 14775.47 tons of carbon dioxide, 99.24 tons of sulfur compounds, 93.82 tons of nitrogen oxides and 57.74 tons of dust in 25 years. This is equivalent to planting more than 6,000 trees in Beijing. It has a positive effect on Beijing's environmental protection and reduction of air pollution.

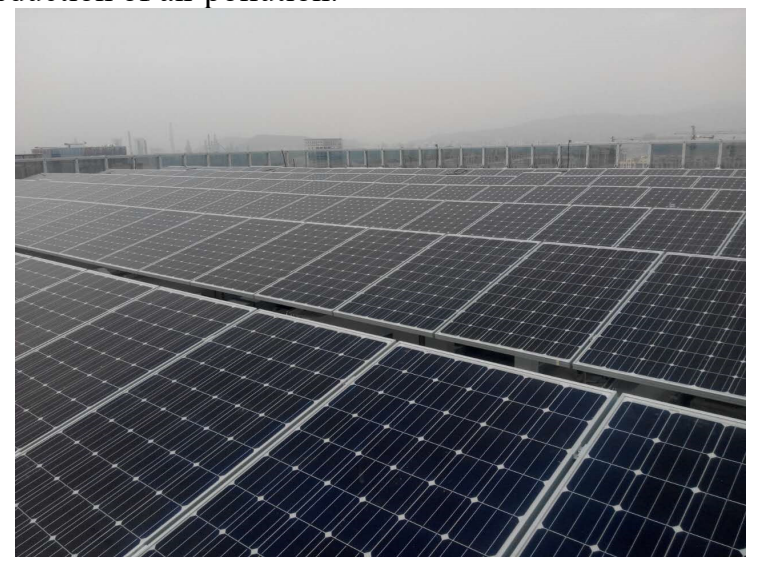

Fig.3 solar photovoltaic power generation system

\subsection{High efficiency electromechanical system}

\subsubsection{Heating, ventilation and air conditioning}

(1) High efficiency equipment and systems

The annual energy consumption of the heating, ventilation and air conditioning system in this project is $70.85 \mathrm{kwh} /(\mathrm{m} 2 \bullet \mathrm{a})$. Compared with the reference buildings, the energy consumption of heating, ventilation and air conditioning systems in this project was reduced by $10.85 \%$. 
The energy efficiency of the largest refrigerating unit is $12 \%$ higher than the national energy saving standard. The heat consumption ratio of the hot water circulating pump in the heating system and the power consumption per unit air volume of the fan in the air conditioning ventilation system all meet the current national standards. Moreover, the conveying energy efficiency of the airconditioning system is $20 \%$ lower than the current national standard. The domestic water pump adopts frequency conversion starting mode, other fans, submersible sewage pumps, elevator and other equipment adopt energy-saving measures. The air conditioning cooling water, cooling water circulating pump, cooling tower all adopt frequency conversion starting mode.

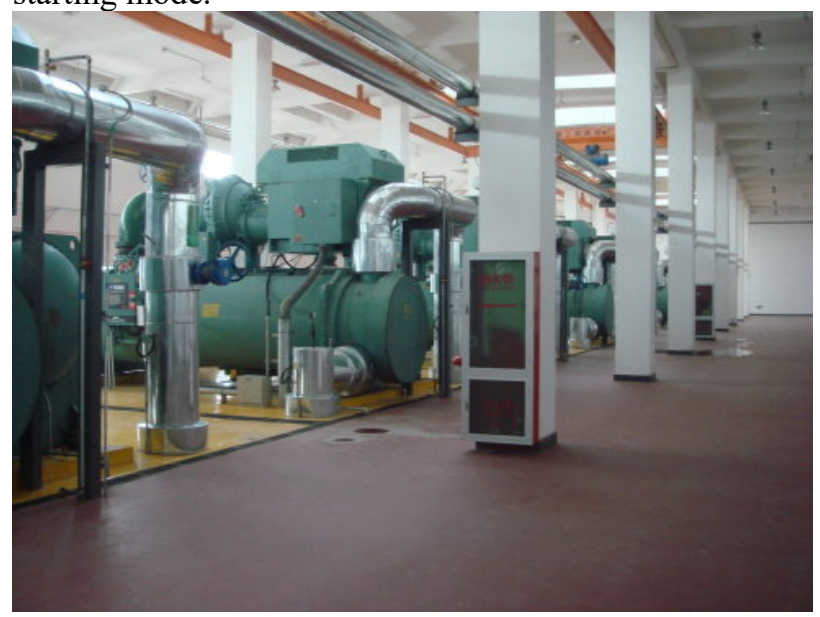

Fig.4 Refrigerating unit

(2) Measures to reduce energy consumption of heating, ventilation and air conditioning systems in transition seasons

In this project, the underground business district, hotel multi-function hall, Chinese restaurant and other large Spaces are equipped with double-fan all-air airconditioning unit or single-fan all-air air-conditioning unit + exhaust fan system. In transition season and winter, it can adjust the ratio of new and return air according to the enthalpy of indoor and outdoor, and make full use of the outdoor fresh air to cool the commercial space in the inner area. Maximum fresh air ratio reaches $100 \%$.

Natural cold sources are used for air conditioning supply in underground commercial space in winter. Fan coil system adopts cooling tower for cooling.

Measures shall be taken to reduce the energy consumption of heating, ventilation and air conditioning systems in the case of partial load and partial space use.

\subsubsection{Lighting and electrical equipment}

\section{(1) energy-efficient lighting}

LED lamps and T5 lamps are used for lighting in this project, which are more than $50 \%$ energy saving compared with ordinary lighting lamps.

(2) energy-saving control measures

Lighting of machine room, storage room, office room, toilet and various vertical shafts of equipment in this project is controlled by lighting switch on the spot. BA control system is adopted in underground garage, corridor, elevator hall and lobby.

(3) Energy saving elevator

The elevator of this project adopts products with high efficiency motor and advanced control technology. Escalators and automatic sidewalks have energy-saving drag and control devices. And sensors are installed to automatically control the operation of escalators and sidewalks. Parallel control is adopted for 2 sets installed simultaneously, group control is used for 3 sets or above. (4) Energy-saving electrical equipment

Three-phase distribution transformer, water pumps, fans and other electrical devices meet the requirements of the current national standards for energy conservation assessment.

\subsubsection{Comprehensive utilization of energy}

For building $1 \sim 6$, every floor of the office area is equipped with a rotary full heat recovery fresh air unit to recycle the exhaust air and save energy. The total heat recovery efficiency is over $60 \%$. In winter, $1.28 \times$ $106 \mathrm{kWh}$ of heat can be saved, in summer, $119140.91 \mathrm{kWh}$ of electricity can be saved, and the annual operating cost can be saved 5115 thousand yuan.

For building $7 \sim 9$, each room is equipped with a full heat recovery fresh air ventilation system. The total heat recovery efficiency is over $65 \%$. In winter, $9.29 \times$ $105 \mathrm{kWh}$ of heat can be saved, in summer, $198678.91 \mathrm{kWh}$ of electricity can be saved, and the annual operating cost can be saved 4681 thousand yuan.

\section{4 air cleaning system}

In view of the poor air quality in Beijing, the project adopts PM2.5 air filtration technology. Air conditioning units and fresh air units in the underground business district are equipped with medium effect filters. Uv disinfection devices are installed in all air conditioning units. The fresh air units in the office area are equipped with primary filter + medium filter + bipolar electrostatic dust removal + ultraviolet disinfection.

Through the combination of large air volume fresh air system and PM2.5 filtration system, indoor dirty air can be transformed into outdoor air. At the same time, through the PM2.5 filtration system, electrostatic dust removal system, humidification system, the outdoor air can be filtered layer by layer. It can effectively block the hair, fibers, dust and other particles in the air, as well as PM2.5, second-hand smoke, soot, pollen and other microscopic particles. It plays a good role in blocking and filtering, so that the solid particles in the air can be purified completely without omission. The removal rate is over $90 \%$.

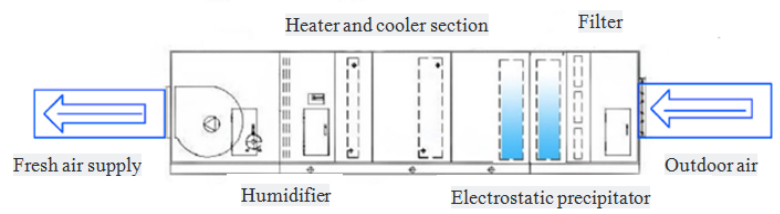

Fig.5 Air cleaning system 


\subsection{Building intelligent control system}

(1) The project adopts advanced building intelligence system to control all the mechanical and electrical equipment of the project. The system can collect operating conditions of all equipment, record indoor and outdoor temperature and humidity, control the opening and operating frequency of equipment to achieve the purpose of energy saving.

(2) Adjust and control the indoor temperature intelligently. And the temperature of each region is controlled separately.

(3) Collect indoor air PM2.5 and $\mathrm{CO}_{2}$ indicators timely to control the operation of fresh air system and air purification equipment so that the healthy quality of indoor air can be ensured.

(4) The project develops an energy management system which can collect energy consumption data, generate statistical analysis report, establish the key performance indicators assessment system and issue alerts for exceeding the limit. It can provide accurate, complete and timely energy consumption of key equipment to provide support to management decision makers.

\subsection{Multiple green system}

The project introduces the concept of multiple greening and elaborates the triple greening landscape with 20,000 $\mathrm{m}^{2}$ municipal theme park along Chang 'an Street, $7000 \mathrm{~m}^{2}$ central park and more than $2000 \mathrm{~m}^{2}$ roof garden. While enriching the landscape layers, it effectively insulates the indoor thermal energy, enhances the green vision rate, and reduces the regional heat island effect.

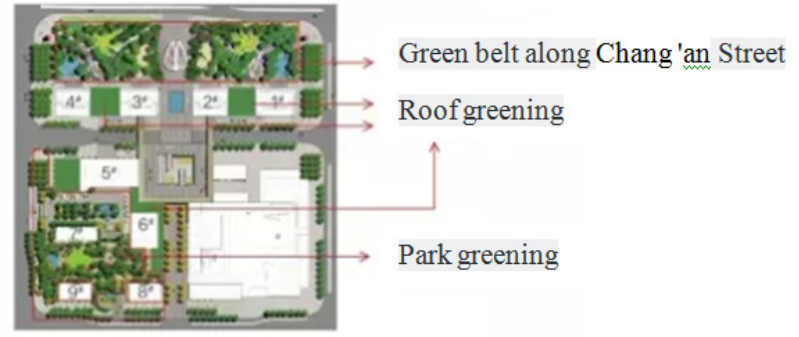

Fig.6 Project greening system diagram

In the garden planting design, plants that adapt to the climate and soil conditions in Beijing are selected, such as spruce, white pine, acer truncatum, magnolia, ginkgo, prunus persica, red maple and cherry. The combination of trees, shrubs and grass is adopted in the multi-layer greening. No less than 3 trees are planted on every 100 square meters of green space. The covering depth of roof planting area is about $1.2 \mathrm{~m}$. The covering depth of basement roof is about $0.6 \sim 3.0 \mathrm{~m}$. They all meet the requirement of covering soil depth of $0.3 \mathrm{~m}$ in Beijing. They are also equipped with hydrophobic boards and aqueducts whose drainage capacity can meet the needs of plant growth.

\subsection{Basement natural lighting system}

As the project underground space is large, natural lighting is insufficient, the project adopts basement natural lighting system to make the best use of natural resources and provide a healthy lighting environment for underground space. Through three sunken squares on the north side, the roof lights of the north commercial corridor, the sunken square on the east side, the roof lights above the central swimming pool, 14 light pipes with the diameter of $530 \mathrm{~mm}$ in the parking lot, the natural lighting condition of B1 layer is. greatly improved. The natural lighting area of the basement can reach 2500 square meters. The results show that the area whose natural lighting coefficient is not less than $0.5 \%$ of this floor is $12.31 \%$ of the total area.

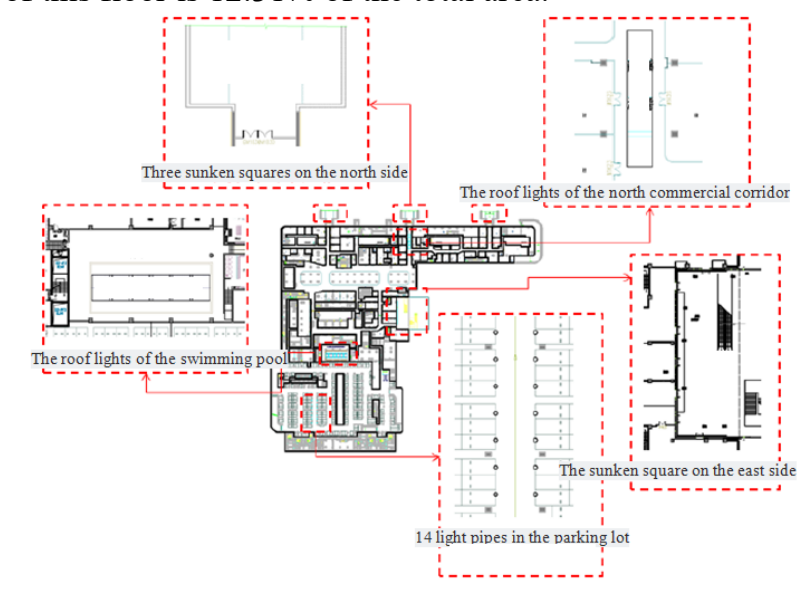

Fig.7 Basement natural lighting system
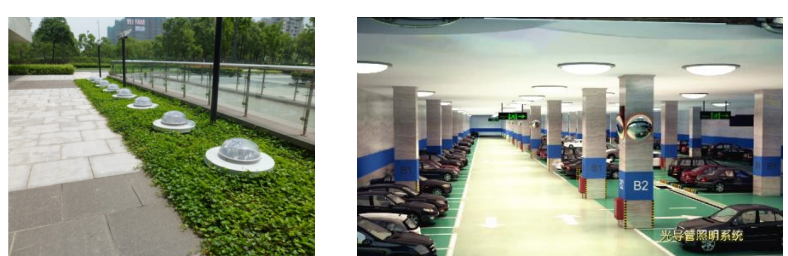

Fig.8 Lightpipe lighting system

The lightpipe lighting system consists of three parts: lighting hood, lightpipe and diffuser. Outdoor natural light is captured by outdoor lighting device, and imported into internal system, and then after strengthened by the optical devices and efficiently transmitted, converted to natural light and diffused evenly into any area of the room that requires light at last. From dawn to dusk, even on cloudy or rainy days, the lighting system still gets enough light into the room.

The lightpipe lighting system can make full use of sunlight, save a lot of lighting electricity, and indirectly reduce the consumption of natural resources and harmful gas emissions.

\subsection{Rainwater control and utilization system}

Beijing is a city of water shortage. Meanwhile, Beijing is prone to waterlogging due to heavy rain during the rainy season. In view of this situation, the project adopts three adjustment measures of concave green space, reservoir and permeable ground, so that the total annual runoff 
control rate of the site can reach more than $70 \%$ and the adjustment and utilization of rainwater is realized.

Project sets concave green space which is $7795 \mathrm{~m}^{2}$. The concave green space uses the open space to receive and store rainwater, which can supplement groundwater, stagnate flood and reduce runoff pollutants. The concave green space for rainwater storage can slow down the flow of water and prolong the storage time. When it rains, a natural "reservoir" can be formed. In addition, the roof greening area is $2149 \mathrm{~m}^{2}$, and the landscape water area is $181 \mathrm{~m}^{2}$ in this project. The total area of greenbelt and water with rainwater storage function accounts for $57 \%$ of the total area of greenbelt.

The project is equipped with $12109 \mathrm{~m}^{2}$ permeable brick paving, accounting for $74 \%$ of the hard paving ground. In this way, the rainwater infiltration will be increased, the rainwater runoff will be reduced, the groundwater ecology will be preserved, the conversion of rainwater, soil water and groundwater will be promoted, and the balance of water circulation system will be maintained.

The project sets up a rainwater storage pool of $800 \mathrm{~m}^{3}$ and a rainwater collection pond of $300 \mathrm{~m}^{3}$. The rainwater recovery and utilization system collect roof rain water and road rain water, and discharge the initial rain water. After precipitation, filtration and disinfection treatment, it can be used for landscape use and green irrigation.

Through these measures, the external discharge of rainwater does not exceed the natural landform before construction. It protects the original site ecology and reduces the impact of development and construction on municipal facilities. At the same time, it can save water effectively.

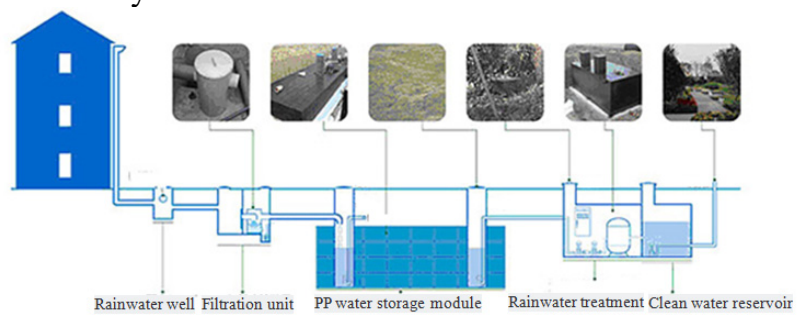

Fig.9 Rainwater control and utilization system

\section{Conclusions}

Through the innovation and application of key technologies for green、 low-carbon and energy-saving buildings, Financial Street Chang 'an Center has achieved remarkable economic, environmental and social benefits. The operating cost can be reduced by 7 million yuan per year, and the carbon emission can be reduced by 211 kilograms per square meter. The project alleviates the pressure on local infrastructure construction and improves people's working and living environment. It has become the example of high-end green development in Shijingshan district of Beijing and played a good demonstration role in the construction of green buildings of urban complex type.

\section{References}

1. China Academy of Building Research. Evaluation standard for green building GB/T50378-2014 [S]. Beijing: China Architecture \& Building Press

2. China State Construction Engineering Corporation. Evaluation standard for green construction of building GB/T50640-2010 [S]. Beijing: China Planning Press

3. China Academy of Building Research. 10 new technologies on the construction industry[M]. Beijing: China Architecture \& Building Press

4. Zhang Jichao. Innovation and practice of key technologies for green, low-carbon and energy saving buildings[M]. Beijing: Science Press

5. Zhang Zhixue. Questions and answers on building energy saving technology[M]. Beijing: Chemical Industry Press 